\title{
Delineating the Molecular Mechanism behind Regulation of Spermatogenesis by Selenium: Involvement of Mitogen Activated Protein Kinase; JNK
}

\author{
Pavitra Ranawat and M.P. Bansal*
}

Department of Biophysics, Panjab University, Chandigarh, India

*Corresponding Author:

M.P. Bansal

Department of Biophysics

Panjab University,

Chandigarh160014, India

Email: mpbansal@pu.ac.in

Tel: 0172-2534120

Fax: 0172-2534118

Received: 6 March 2009; $\mid$ Revised: 29 April 2009; | Accepted: 3 May 2009

\begin{abstract}
Selenium is required for maintenance of male fertility. It regulates cell growth, cytotoxicity and transformation. Previous studies from our lab demonstrated inactivation of transcription factor AP-1 by selenium status. Nonetheless, the modulatory functions of selenium and other selenium compounds on intracellular signaling pathways involving the MAPKs are not fully understood. The mitogen- activated protein kinase (MAPK) pathway is one of the most widely studied signaling pathways involved in the transduction of intracellular signals initiated by extracellular stimuli to the nucleus. Amongst MAPKs, the cjun N- terminal kinase (JNK MAPK) is an upstream kinase for transcription factor, Activator protein (AP-1). AP-1 plays a role in cell proliferation and transformation; and is sensitive to oxidants, anti-oxidants and conditions which affect the cellular redox state. In this respect, the upstream kinase for AP-1, JNK MAPK, might also be sensitive to the selenium status. Thus, to delineate the molecular pathway involved in the selenium action as a regulator of spermatogenesis, the upstream kinase for AP-1, the JNK MAPK was explored further under selenium stress conditions. Different selenium status-deficient, adequate and excess selenium were generated in male mice by feeding respective diets for a period of 4 and 8 weeks. Selenium status and GSH-Px activity was checked in testis. The reproductive potential of mice was affected at these altered selenium levels. There was a decrease in the SOD activity and reduced glutathione levels concomitant with an increase in the oxidized glutathione levels, indicative of oxidative stress. mRNA expression of GSH-Px, MnSOD and $\gamma$ GCS was found to be altered. There was an increase in the mRNA and protein expression of JNK MAPK which was further confirmed by its immunohiostochemical localization studies. Thus, the study clearly shows that JNK MAPK, an upstream kinase for AP-1 regulates spermatogenesis independently of AP-1. The decrease in reproductive potential as observed in the present study might result from the alteration in the redox environment of the testicular compartment.
\end{abstract}


Keywords: Selenium; AP-1; JNK MAPK; spermatogenesis; male fertility.

\section{Introduction}

Selenium (Se) is required for maintenance of male fertility [1] and is used for the synthesis of about a dozen selenoproteins [2; 3], most of which have reactive oxygen species (ROS) scavenging activities.

Selenium containing antioxidant enzyme GPx family includes the classical GPx (cGPx,GPx 1), gastrointestinal GPx (GI-GPx), plasma GPx (pGPx), phospholipid GPx (PHGPx), epididymal GPx (GPx 5) and sperm nucleus GPx (sn GPx) [4; 5]. The expression and activity of GPx 4 are highest in the testis [6] where it has a peroxidase function in the late spermatids [7]. Se deficiency leads to GPx 4 depletion and structural defects in the spermatozoa leading to loss of motility and reduced fertility [8]. GPx 1 mRNA is affected by Se status while GPx 4 and other selenoproteins are less regulated by Se-status [6;9].

Seleno- compounds also possess anti- cancer properties [2]. The anti- cancer effects were suggested to be an inhibitory action on cell proliferation in various tumor cells. The cytotoxic activity of selenite is suggested to be associated with oxidative stress [10] and interaction with thiol groups of proteins [11].

Selenium has been linked to regulatory functions in cell growth, cytotoxicity and transformation [12]. It appears to modulate such cellular activities presumably by acting on proteins important for signal transduction [13; 14]. Nonetheless, the modulatory functions of Se and other Se compounds on intracellular signaling pathways are not fully understood. The mitogenactivated protein kinase (MAPK) pathway is one of the most widely studied signaling pathways. MAPKs play pivotal roles in a variety of cell activities, such as cell proliferation, differentiation, developments and survival [15] and include:

ERK MAPK, JNK/SAPK and p38 MAPK $[16 ; 17]$. ERK is activated when cells are exposed to mitogens $(15 ; 18]$. JNK/SAPK is activated in response to variety of cellular stresses [16;17]. p38
MAPK can also be activated by various stresses [19]. JNK and p38 MAPK seem to be involved in stress- activated cellular events that can include cell death [20;21].

Activation of JNK results in the phosphorylation and activation of the transcription factor c-Jun [22]. Activator Protein 1(AP-1) plays a role in cell proliferation and transformation; and is sensitive to oxidants, anti-oxidants and conditions which affect the cellular redox state [23]. Potent AP-1 sites occur in the promoter regions of various genes related to antioxidant defense, such as $\gamma \mathrm{GCS}$ and superoxide dismutase; Mn SOD [24]. Thus, the levels of these enzymes might also change with altered Se status and changing levels of AP-1, thus disturbing the oxidative environment. The antioxidant and anticancer effects of Se might be mediated by AP-1. In this respect, the upstream kinase for AP-1; JNK MAPK, might also be sensitive to Se status. Previous in vitro studies [25] have reported activation of JNK MAPK under Se stress and glutathione deprived conditions. Also, previous in vivo studies [26] reported inactivation of AP-1 by Se via a redox control mechanism.

Thus, to delineate the molecular pathway involved in $\mathrm{Se}$ action as a regulator of spermatogenesis, the upstream kinase for AP-1, the JNK MAPK was explored further under Se stress conditions. The study investigated the effect of $\mathrm{Se}$ status on testicular development and spermatogenesis by evaluating the changes in the activity and mRNA expression of antioxidant enzymes and by evaluating the reproductive potential in mice due to changed Se levels. These studies are hoped to help in elucidating the role of $\mathrm{Se}$ in regulating spermatogenesis at molecular level.

\section{Materials and Methods}

Chemicals: Sodium selenite $\left(\mathrm{Na}_{2} \mathrm{SeO} 3\right), 2,3-$ diaminonapthalene (DAN), Agarose, Ethidium bromide and Proteinase $\mathrm{K}$ were purchased from Sigma-Aldrich (St. Louis, MO, USA). TRI- 
reagent and one-step RT-PCR kit were obtained from Molecular Research Centre (Inc. Cincinnati; Ohio) and QIAGEN, respectively. Oligonucleotides were synthesized by SigmaAldrich. Molecular biology grade chemicals for RNA isolation e.g. chloroform, isopropanol, ethanol and formaldehyde were purchased from Amresco, Ohio (USA). Antibody against JNK, peroxidase conjugated anti-rabbit secondary antibody and anti-mouse $\beta$-actin were purchased from Sigma-Aldrich, St Louis (USA). All other chemicals and reagents used in the present study were of analytical grade and were procured from the Indian manufacturers.

Animal procurement and treatment schedule: Male Balb/c mice in the weight range of 20-25g were used in the present study. To make different Se status animals viz. 0.02ppm, $0.2 \mathrm{ppm}$ and $1 \mathrm{ppm}$, in different groups (Group I, II and III respectively), the mice were kept on yeast-based diet. The yeast-based diet usually contains 0.02 ppm Se and hence animals fed on this diet were considered Se deficient animals (Group I). For Se supplemented groups, Se was added at $0.2 \mathrm{ppm}$ (Group II; adequate level) and 1ppm (Group III; excess level) as sodium selenite to Se deficient diet. All the animals were fed with the respective diets for 4 weeks (Group Ia, IIa and IIIa) and 8 weeks (Group Ib, IIb and IIIb).

Selenium Deficient Diet: Selenium deficient diet with inactivated Baker's yeast as a protein source was prepared in the laboratory itself according to the composition given by Burk [27].

Selenium estimation: Selenium levels in testis were estimated as according to the fluorometric method [28]. The method is based on the principle that $\mathrm{Se}$ in tissues on acid digestion is converted into selenous acid, which on reaction with aromatic-o-diamines such as 2,3-diamine naphthalene (DAN) leads to the formation of 4,5benzopiazselenol, which displays brilliant lime green fluorescence. Briefly, 100mg of testis tissue was acid digested in concentrated $\mathrm{HNO}_{3}$ on a sand bath at approx. $100^{\circ} \mathrm{C}$ in digestion flasks fitted with long air condenser to prevent any Se vapour loss. A known amount of digest was reacted with aqueous solution of DAN (precleaned of impurities with cyclohexane). The product (4,5benzopiaselenol) formed was extracted completely with cyclohexane and quantitated on fluorescence spectrophotometer (Perkin Elmer, USA) using $366 \mathrm{~nm}$ as excitation and $520 \mathrm{~nm}$ as emission wavelength. Sodium selenite was used as standard for this assay.

Biochemical estimations: $10 \%(\mathrm{w} / \mathrm{v})$ tissue homogenates were prepared in $50 \mathrm{mM}$ Tris- $\mathrm{HCl}$ ( $\mathrm{pH}$ 7.4) under ice-cold conditions. The homogenates were then centrifuged at $10,000 \mathrm{rpm}$ for 30 minutes. The supernatant (post mitochondrial fraction, PMF) thus obtained was collected for the biochemical estimations described below.

Glutathione peroxidase activity: Activity of glutathione peroxidase (GSH-Px) was assayed by the coupled enzyme procedure with glutathione reductase using $\mathrm{H}_{2} \mathrm{O}_{2}$ as substrate [29]. The assay was carried out in testis PMF. The activity was expressed as $\mu$ moles of NADPH oxidized $/ \mathrm{min} / \mathrm{mg}$ protein. Total protein was estimated by the method of Lowry et al. 1951.

Oxidized and reduced glutathione: GSH and GSSG were quantitated by the method of Hissin and Hilf [30] using o- pthaldehyde (OPT), which forms a highly fluorescent conjugate with GSH. This method is based on the reaction of GSH at $\mathrm{pH} 8$ and GSSG at $\mathrm{pH} 12$. GSH is complexed to $\mathrm{N}$ - ethylmaleimide (NEM) to prevent interference of GSH with the measurement of GSSG. GSH levels were obtained by subtracting the levels of GSSG from total glutathione levels. Protein was estimated by the method of Lowry et al. 1951. The results were expressed as nmoles of $\mathrm{GSH}$ or GSSG per mg protein.

Superoxide dismutase (SOD): Total SOD activity was determined in testicular PMF by the method of Kono [31]. The reaction is based on the principle of inhibition of the rate of oxidation of nitro blue tetrazolium (NBT) using hydroxylamine hydrochloride as the electron donor.

\section{Evaluation of reproductive potential:}

Sperm counts in epididymis and sperm motility in vas deferens: At the time of sacrifice, epididymal spermatozoa were squeezed out in $1 \mathrm{ml}$ saline. Sperm number was counted in haemocytometer and expressed as sperm counts per $\mathrm{mm}^{3}$.

(C) 2009 by NWPII. All rights reserved. 
For sperm motility, the spermatozoa from vas deferens were flushed out into $0.2 \mathrm{ml}$ normal saline. Number of motile and nonmotile sperms was counted under light microscope. Motility was expressed as percentage of motile sperms.

RNA isolation: Total RNA was isolated from mice testis using TRI-REAGENT (Mol Res. Centre, Inc, Ohio, USA). Purity, integrity and concentration of the isolated RNA were checked by first taking absorbance at 260 and $280 \mathrm{~nm}$ and finding their ratio and then by $1.2 \%$ formaldehyde agarose gel electrophoresis. Concentration of RNA was estimated by using A $260=1=40 \mu \mathrm{g} / \mathrm{ml}$.

Primer designing and synthesis for RT-PCR analysis: For the RT-PCR analysis, the DNA sequence for JNK was searched from the computer data base. Primers for JNK were designed from the sequence data with the help of software "Gene Runner" and were got synthesized from Sigma Aldrich (USA). Length of the primers chosen was $\sim 20 \mathrm{bp}$. Primer sequences for different genes are given in Table I.

\section{Table I: Primer sequences}

\begin{tabular}{|c|c|c|c|}
\hline Gene & Primer & Reference & Product size \\
\hline JNK & $\begin{array}{l}\text { Sense 5' TCC AGC ACC CAT ACA TCA AGG 3' } \\
\text { Antisense 5' ACC CAA GGC CCA AGT AGT CAT C 3, }\end{array}$ & ВC053027 & $324 b p$ \\
\hline$\beta$-actin & $\begin{array}{l}\text { Sense 5' ATC CGT AAA GAC CTC TAT GC 3' } \\
\text { Antisense 5' AAC GCA GCT CAG TAA CAG TC 3' }\end{array}$ & {$[52]$} & $287 b p$ \\
\hline GSH-Px & $\begin{array}{l}\text { Sense 5' CCT CAA GTA CGT CCG ACC TG-3' } \\
\text { Antisense 5' CAA TGT CGT TGC GGC ACA CC-3' }\end{array}$ & $\{53\}$ & 197bp \\
\hline г GCS & $\begin{array}{l}\text { Sense 5' CCT TCT GGC ACA GCA CGT TG-3“' } \\
\text { Antisense 5' TAA GAC GGC ATC TCG CTC CT-3' }\end{array}$ & [54] & $346 b p$ \\
\hline MnSOD & $\begin{array}{l}\text { Sense 5' GCA CAT TAA CGC GCA GAT CA-3' } \\
\text { Antisense 5' AGC CTC CAG CAA CTC TCC TT-3' }\end{array}$ & [55] & $241 b p$ \\
\hline
\end{tabular}

RT-PCR procedure: RT-PCR was done using specific primers for the respective genes. RT-PCR for $\beta$-actin was also done alongwith to rule out the experimental errors. QIAGEN one step RT-PCR kit was used for the purpose. Two $\mu \mathrm{g}$ of total RNA was used in RT-PCR reaction from different groups. The PCR reaction was performed in the thermal cycler (Techne Ltd, England) using following conditions: RT reaction was performed at $50^{\circ} \mathrm{C}$ for $50 \mathrm{~min}$ and activation at $94^{\circ} \mathrm{C}$ for 15 min. PCR was followed by 35 cycles of $94^{\circ} \mathrm{C}$ (denaturation) for $45 \mathrm{sec}, 56^{\circ} \mathrm{C}$ (annealing) for 45 sec, $68^{\circ} \mathrm{C}$ (extension) for $1 \mathrm{~min}$. Finally, the products were incubated at $68^{\circ} \mathrm{C}$ for $5 \mathrm{~min}$ to extend any incomplete single strands. To authenticate the results from RT-PCR (a semiquantitative method) analysis, initially RTPCR for various genes was carried at 20, 25, 30, and 35 cycles. Progressive increase in products was obtained in all cases and hence finally the RTPCR was done with the samples at 35 cycles only. Final PCR products formed were analyzed on $1.5 \%$ agarose gel electrophoresis and densitometric analysis of the bands was done by Image $\mathbf{J}$ software (NIH, USA). Mean of four independent densitometric analyses of PCR product bands were determined for comparison of each analysis.

Western Immunoblot Analysis: Protein samples $(60 \mu \mathrm{g})$ from each treatment group were separated on $10 \%$ SDS-PAGE. The separated proteins were electrophoretically transferred to (C) 2009 by NWPII. All rights reserved. 
PVDF membrane (Millipore, USA). Immunoblot was prepared using antimouse anti-JNK primary antibody (Sigma-Aldrich) and peroxidase conjugated anti-rabbit IgG secondary antibody (Sigma-Aldrich). Diaminobenzedine (DAB) plus $\mathrm{H}_{2} \mathrm{O}_{2}$ detection system was used to develop the blot. Bands obtained were densitometrically analyzed using Image $\mathbf{J}$ software and the density expressed as ratio of densitometric units. For preparation of cell lysate, testes were collected from the different treatment groups after completion of diet feeding schedule of 4 and 8 weeks. Total lysates were prepared in fresh icecold protein lysis buffer $(50 \mathrm{mM}$ Tris $\mathrm{pH} 7.5,150$ $\mathrm{mM} \mathrm{NaCl}, 0.1 \%$ NP-40, $50 \mathrm{mM} \mathrm{NaF}, 1 \mathrm{mM}$ $\mathrm{Na}_{3} \mathrm{VO}_{3}, 1 \mathrm{mM}$ PMSF). The extracts were cleared by centrifugation at $440 \mathrm{~g}$ for 10 minutes at $4^{\circ} \mathrm{C}$. The supernatants were collected and protein concentration was determined individually by method of Lowry et al.

Immunohisochemical localization studies: $6 \mu \mathrm{m}$ thick paraffin sections of mice testis were deparaffinized in two changes of xylene for 30 min each. The sections were then gradually hydrated and brought to water. Endogenous peroxidase activity was blocked by incubation with $3 \% \mathrm{H}_{2} \mathrm{O}_{2}$ for $30 \mathrm{~min}$ at $37^{\circ} \mathrm{C}$. The non specific staining was blocked by incubating sections with $2 \%$ BSA in phosphate buffer saline (PBS $10 \mathrm{mM}$, $\mathrm{pH}$ 7.2). The sections were then incubated with polyclonal antibody against JNK (Sigma Aldrich; $1: 8000)$ in a moist chamber for $1 \mathrm{hr}$ at $37^{\circ} \mathrm{C}$. After incubation, the sections were washed in PBS, PBS tween (PBS with $0.05 \%$ tween-20) and PBS successively for $5 \mathrm{~min}$ each. The sections were then incubated with peroxidase labeled anti-rabbit IgG (1:500) for $1 \mathrm{hr}$. Sections were washed again in the same manner as described above and the reaction product was developed using diaminobenzidine (DAB) and $\mathrm{H}_{2} \mathrm{O}_{2}$. Reaction was terminated by washing with distilled water after which sections were mounted in glycerol jelly.

Microscopy and Data analysis: Sections were viewed and photographed with a Leica Optiphot microscope to which was attached a Leica Digital camera. For each testicular cross section, all crosssectional tubular profiles $(\sim 100-150)$ were counted.

Statistical analysis: The difference between Means \pm Standard Deviations (SD) for control and treated groups were examined by using the Student's t-test for unpaired values. Statistical difference of p-value at the level of 0.05 or less was considered significant.

TABLE II: Selenium status and glutathione peroxidase activity after 4 and 8 weeks diet feeding schedule.

\begin{tabular}{|c|c|c|c|c|c|c|}
\hline & $\begin{array}{l}\text { Se Deficient } \\
\text { Gp Ia }\end{array}$ & $\begin{array}{c}\text { Se Adequate } \\
\text { Gp IIa }\end{array}$ & $\begin{array}{l}\text { Se Excess } \\
\text { Gp IIIa }\end{array}$ & $\begin{array}{l}\text { Se Deficient } \\
\text { Gp Ib }\end{array}$ & $\begin{array}{l}\text { Se Adequate } \\
\text { GpIIb }\end{array}$ & $\begin{array}{l}\text { Se Excess } \\
\text { Gp IIIb }\end{array}$ \\
\hline $\begin{array}{l}\text { Selenium estimation } \\
\text { ( } \mu \text { g Seg tissue) }\end{array}$ & $0.562=0.015(a)$ & $0.723=0.018$ & $0.842=0.04(\mathrm{~b})$ & $0.429=0.017(\mathrm{c}, \mathrm{d})$ & $0.701=0.016$ & $0.927=0.03(e, f)$ \\
\hline $\begin{array}{l}\text { Glutathione peroxidase } \\
\text { ( } \mu \text { moles of NADPH } \\
\text { oxidized min mg protein) }\end{array}$ & $85.87=1.12(\mathrm{~g})$ & $119.23=1.60$ & $148.57=3.27(\mathrm{~h})$ & $47.85=1.10(\mathrm{i}, \mathrm{j})$ & $114.46=3.69$ & $132.17=1.43(\mathrm{k})$ \\
\hline
\end{tabular}

Values are Mean $\pm S D$ of 6 observations. a(0.00012), b(0.00035), c(0.00062), e(0.00041), $g(0.00078), h(0.00081)$, $i(0.00030)$ and $k(0.00052)$ represents comparison of Se deficient and Se excess groups with respect to Se adequate groups at 4 and 8 weeks. $d(0.00084), f(1.55 E-05)$ and j(0.0091) represents comparison of Se deficient and Se excess groups at 8 weeks with the respective groups at 4 weeks interval.

\section{Results}

Selenium estimation: The data of Se estimated in mice testis from all the three treatment groups after 4 and 8 weeks of diet feeding is shown in Table II. A significant decrease in Se level was observed in group Ia and group Ib. Significant increase was observed in the Se excess group IIIa and IIIb.

Glutathione peroxidase activity: A significant decrease in the activity of GSH-Px was observed in both Se deficient groups (Ia and Ib) 
when compared to Se adequate groups (IIa and IIb) respectively. On the other hand, significant increase was observed in Se excess group IIIa and $\mathrm{IIIb}$ as compared to the respective Se adequate group IIa and IIb. The data is shown in Table II which further strengthens the observations of establishment of Se status and the prevalence of oxidative stress conditions in the testicular compartment.
Glutathione levels: The levels of oxidized (GSSG) and reduced (GSH) glutathione were estimated in the testis after 4 and 8 weeks in all treatment groups (Table III). A significant increase in the levels of GSSG was observed in Gp Ia which became highly significant in gp Ib as compared to gp IIa or IIb. Significant increase in GSSG was seen in gp IIIb.

TABLE III: Testis glutathione levels and antioxidant enzymes status after 4 and 8 weeks of diet feeding schedule.

\begin{tabular}{|lcccccc|}
\hline & $\begin{array}{c}\text { Se Deficient } \\
\text { Gp Ia }\end{array}$ & $\begin{array}{c}\text { Se Adequate } \\
\text { Gp IIa }\end{array}$ & $\begin{array}{c}\text { Se Excess } \\
\text { Gp IIIa }\end{array}$ & $\begin{array}{c}\text { Se Deficient } \\
\text { Gp Ib }\end{array}$ & $\begin{array}{c}\text { Se Adequate } \\
\text { GpIIb }\end{array}$ & $\begin{array}{c}\text { Se Excess } \\
\text { Gp IIIb }\end{array}$ \\
\hline $\begin{array}{l}\text { GSSG } \\
\text { (nmoles/mg protein) }\end{array}$ & $2.205=0.05(\mathrm{a})$ & $1.247=0.11$ & $1.973=0.02(\mathrm{~b})$ & $3.633=0.1(\mathrm{c}, \mathrm{d})$ & $1.247 \pm 0.08$ & $3.389=0.2(\mathrm{e}, \mathrm{f})$ \\
$\begin{array}{l}\text { GSH } \\
\text { (nmoles/mg protein) }\end{array}$ & $41.81=0.84(\mathrm{~g})$ & $50.69=0.91$ & $38.49=1.25(\mathrm{~h})$ & $34.69=1.1(\mathrm{i}, \mathrm{j})$ & $47.98=2.0$ & $37.25=1.16(\mathrm{k})$ \\
$\begin{array}{l}\text { Redox ratio } \\
\text { (GSH/GSSG) }\end{array}$ & $18.96=0.12(\mathrm{~m})$ & $40.86=3.09$ & $19.5=0.41(\mathrm{n})$ & $9.549=0.02(\mathrm{o}, \mathrm{p})$ & $38.52=1.0$ & $11.03=0.99(\mathrm{q}, \mathrm{r})$ \\
$\begin{array}{l}\text { Superoxide dismutase } \\
\text { (U/mg protein) }\end{array}$ & $1.63=0.06(\mathrm{~s})$ & $2.91=0.08$ & $2.4=0.09(\mathrm{t})$ & $1.81=0.03(\mathrm{u}, \mathrm{v})$ & $2.73=0.12$ & $2.85=0.04(\mathrm{w}, \mathrm{x})$ \\
\hline
\end{tabular}

Values are Mean $\pm S D$ of 6 observations. a(0.00032), b(0.00027), c(2.14E-05), e(1.84E-05), g(0.00030), $h(0.00018)$, $i(0.00012), k(0.00024), m(0.00042), n(0.00040), o(0.00012), q(0.00010), s(3.60 E-06), t(1.55 E-06), u(1.42 E-05)$ and $w(0.042)$ represents comparison of Se deficient and Se excess groups with respect to Se adequate groups at 4 and 8 weeks. $d(1.02 E-05), f(1.02 E-05), j(0.00036), p(0.00024), r(0.00031), v(0.0094)$ and $x(1.64 E-05)$ represents comparison of Se deficient and Se excess groups at 8 weeks with the respective groups at 4 weeks interval.

TABLE IV: Changes in sperm motility and sperm count after 4 and 8 weeks diet feeding schedule.

\begin{tabular}{|c|c|c|c|c|c|c|}
\hline & $\begin{array}{c}\text { Se Deficient } \\
\text { Gp Ia }\end{array}$ & $\begin{array}{c}\text { Se Adequate } \\
\text { Gp IIa }\end{array}$ & $\begin{array}{c}\text { Se Excess } \\
\text { Gp IIIa }\end{array}$ & $\begin{array}{l}\text { Se Deficient } \\
\text { Gp Ib }\end{array}$ & $\begin{array}{l}\text { Se Adequate } \\
\text { GpIIb }\end{array}$ & $\begin{array}{l}\text { Se Excess } \\
\text { Gp IIIb }\end{array}$ \\
\hline
\end{tabular}

Values are Mean $\pm S D$ of 6 observations. a(3.03E-05), b(0.0059), c(16.2E-05), e(0.0072), $g(0.00078), h(0.00084)$, $i(5.01 E-07)$ and $k(3.12 E-07)$ represents comparison of Se deficient and Se excess groups with respect to Se adequate groups at 4 and 8 weeks. d(3.0E-05), f(0.00052), j(4.02E-06) and l(4.34E-06) represents comparison of Se deficient and Se excess groups at 8 weeks with the respective groups at 4 weeks interval.

Significant decrease in the levels of GSH was seen in groups Ia and IIIa, the decrease became highly pronounced in gps Ib and IIIb as compared to their respective controls IIa and IIb.

Significant decrease in redox ratio was observed in gp Ia \& Ib and gp IIIa \& gp IIIb as compared to their respective controls (gp IIa \& gp $\mathrm{IIb})$.

Superoxide dismutase (SOD): SOD activity decreased in Se deficient gp (Ia) and Se excess gp (IIIa). The activity of the enzyme decreased further at the 8 week interval in Se deficient $\mathrm{gp}$ (Ib) as compared to the respective control gp (IIb), 
whereas the activity increased significantly in the Se excess gp (IIIb) at 8 week interval (Table III).

\section{Evaluation of reproductive potential:}

Sperm motility in vas deferens and Sperm counts in epididymis: The fertility status of the treated animals in terms of $\%$ motility as well as sperm count was observed. Data is shown in Table IV. A significant decrease in sperm motility and sperm count was observed in Se deficient groups at both the treatment intervals as compared to their respective control groups. Similarly, significant decrease was also observed in the Se excess groups at both the treatment intervals. However, the decrease was more pronounced in the deficient groups as compared to excess groups at both the treatment intervals. (a)

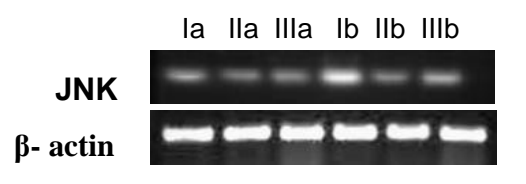

324bp

287bp

Lane la: 4 weeks Se deficient Lane Ila: 4 weeks Se adequate Lane IIla: 4 weeks Se excess Lane Ib: 8 weeks Se deficient Lane Ilb: 8 weeks Se adequate Lane IIIb: 8 weeks Se excess

(b)

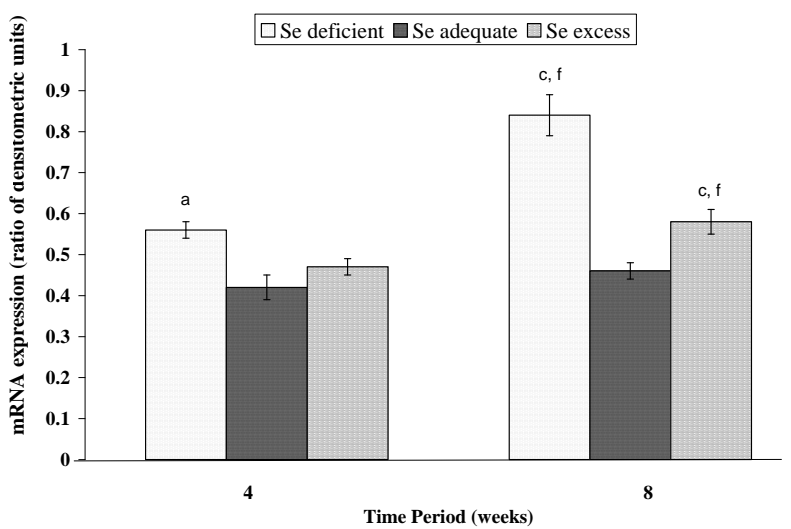

Values are Mean $\pm S D$ of 6 observations. ${ }^{a} p<0.05$ and ${ }^{c} p<0.001$ represents comparison of Se deficient and Se excess groups with respect to Se adequate groups at 4 and 8 weeks. ${ }^{f} p<0.001$ represents comparison of Se deficient and Se excess groups at 8 weeks with the respective groups at 4 weeks interval.

Fig I. Effect of modulation in selenium status on the mRNA expression of JNK (a) and its densitometric analysis (b).

(a)

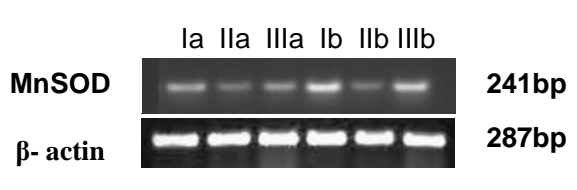

(b)

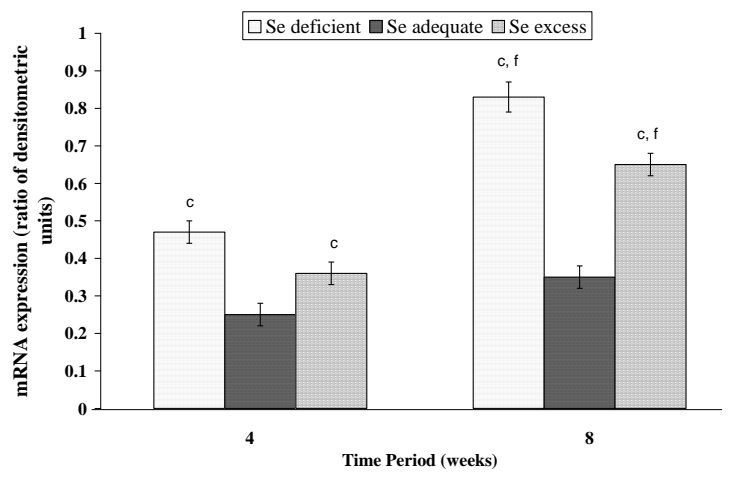

Lane la: 4 weeks Se deficient Lane Ila: 4 weeks Se adequate Lane IIla: 4 weeks Se excess Lane Ib: 8 weeks Se deficient Lane Ilb: 8 weeks Se adequate Lane IIlb: 8 weeks Se excess

Values are Mean \pm SD of 6 observations. ${ }^{c} p<0.001$ represents comparison of Se deficient and Se excess groups with respect to Se adequate groups at 4 and 8 weeks. ${ }^{f} p<0.001$ represents comparison of Se deficient and Se excess groups at 8 weeks with the respective groups at 4 weeks interval.

Fig II. Effect of modulation in selenium status on the mRNA expression of MnSOD (a) and its densitometric analysis (b). 
mRNA expression of JNK and antioxidant enzymes: The mRNA expression for JNK MAPK, MnSOD, GSH-Px and $\gamma \mathrm{GCS}$ along with their densitometric analysis is shown in Fig, I(a,b), Fig II(a,b), Fig III(a,b) and Fig IV(a,b). Significant increase in the mRNA expression of JNK was observed under the conditions of Se deficiency and $\mathrm{Se}$ excess as compared to the respective $\mathrm{Se}$ adequate group. However, this increase was more prominent in the Se deficient group. Also, the increase was more pronounced at the 8 week interval as compared to the 4 week interval. (a)

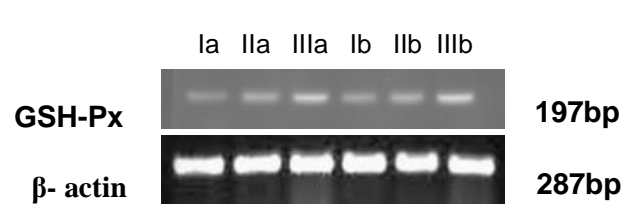

Lane la: 4 weeks Se deficient Lane Ila: 4 weeks Se adequate Lane IIla: 4 weeks Se excess Lane Ib: 8 weeks Se deficient Lane Ilb: 8 weeks Se adequate Lane IIlb: 8 weeks Se excess

(b)

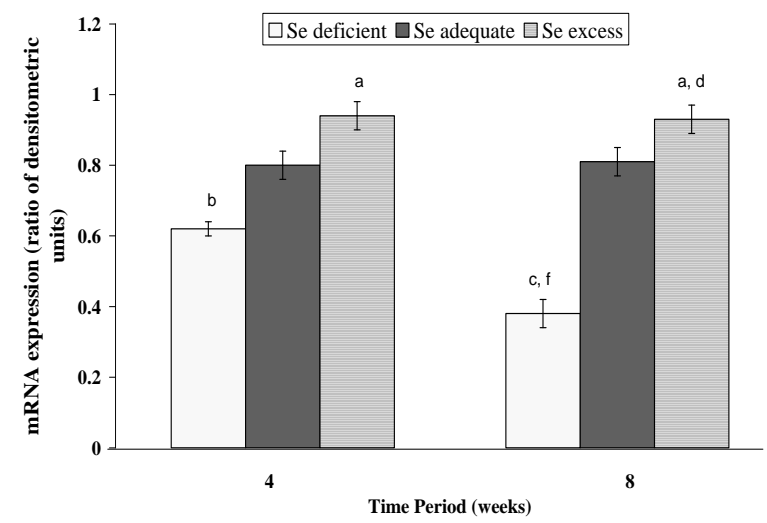

Values are Mean \pm SD of 6 observations. ${ }^{a} p<0.05,{ }^{b} p<0.01$ and ${ }^{c} p<0.001$ represents comparison of Se deficient and Se excess groups with respect to Se adequate groups at 4 and 8 weeks. ${ }^{d} p<0.05$ and ${ }^{f} p<0.001$ represents comparison of Se deficient and Se excess groups at 8 weeks with the respective groups at 4 weeks interval.

Fig III. Effect of modulation in selenium status on the mRNA expression of GSH-Px (a) and its densitometric analysis (b).

(a)

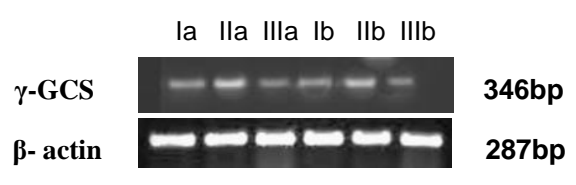

Lane la: 4 weeks Se deficient

Lane Ila: 4 weeks Se adequate

Lane Illa: 4 weeks Se excess

Lane Ib: 8 weeks Se deficient

Lane Ilb: 8 weeks Se adequate

Lane Illb: 8 weeks Se excess (b)

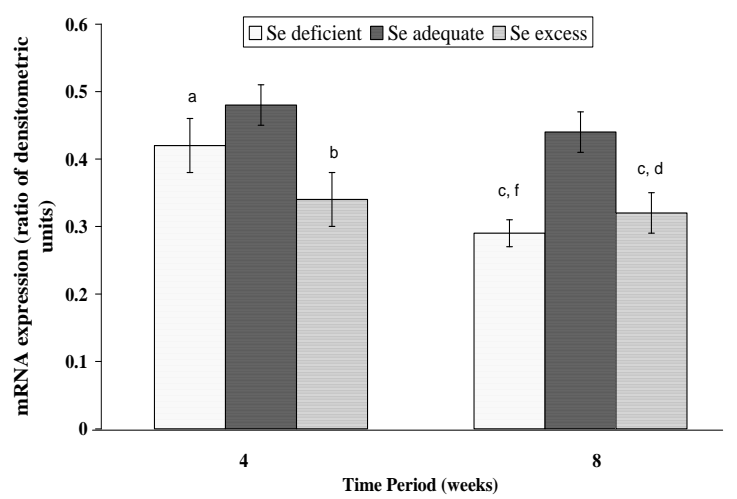

Values are Mean $\pm S D$ of 6 observations. ${ }^{a} p<0.05,{ }^{b} p<0.01$ and ${ }^{c} p<0.001$ represents comparison of Se deficient and Se excess groups with respect to Se adequate groups at 4 and 8 weeks $.{ }^{d} p<0.05$ and ${ }^{f} p<0.001$ represents comparison of Se deficient and Se excess groups at 8 weeks with the respective groups at 4 weeks interval.

Fig IV. Effect of modulation in selenium status on the mRNA expression of $\gamma$-GCS (a) and its densitometric analysis (b).

Small decrease in the GSH-Px expression was seen in the Se deficient group Ia while the expression in Se excess group IIIa increased as compared to Se adequate group IIa. At 8 week duration, the expression of GSH-Px decreased further in the Se deficient group $\mathrm{Ib}$ while no significant increase was observed in the excess group IIIb. In case of $\gamma \mathrm{GCS}$ and MnSOD, little 
change in expression was observed at the 4 week interval. However, at 8 weeks, a decrease in mRNA expression for $\gamma \mathrm{GCS}$ and increase in expression for MnSOD was observed in Se deficient group and Se excess group.

Western Immunoblot Analysis: To ascertain whether activation of mRNA expression of JNK under Se status also led to an increase in the protein product; Western immunoblot analysis for JNK MAPK was done as shown in Fig V(a,b). The results obtained clearly demonstrate significant increase in the protein expression of JNK under Se deficient and Se excess conditions as compared to the respective $\mathrm{Se}$ adequate conditions. However, this increase was more prominent in the Se deficient group. Also, the increase was more pronounced at the 8 weeks interval as compared to the 4 weeks interval. The results obtained demonstrate that an increase in the mRNA expression finally caused an increased protein expression under Se stressed conditions.

\section{Immunohistochemical localization studies:}

To look for the cell specific expression of JNK MAPK we performed JNK immunostaining in all the treatment groups. It was observed that all cell types stained positive for JNK MAPK, but the frequency of each cell type varied under different Se status from four to eight weeks (Fig VI). (a)

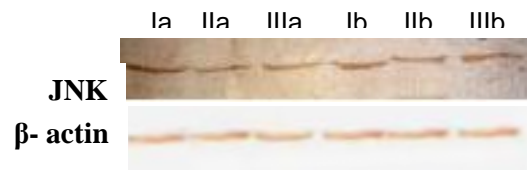

Lane la: 4 weeks Se deficient Lane Ila: 4 weeks Se adequate Lane IIla: 4 weeks Se excess

Lane Ib: 8 weeks Se deficient

Lane IIb: 8 weeks Se adequate

Lane IIlb: 8 weeks Se excess (b)

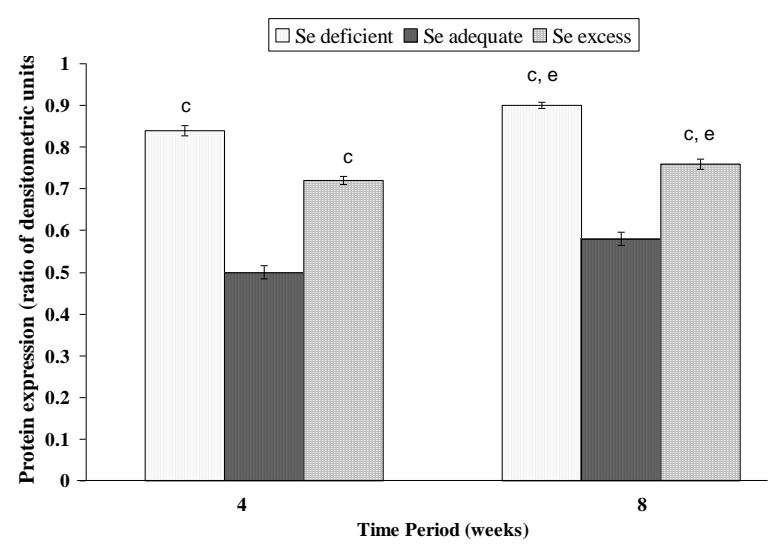

Values are Mean $\pm S D$ of 6 observations. ${ }^{c} p<0.001$ represents comparison of Se deficient and Se excess groups with respect to Se adequate groups at 4 and 8 weeks. ${ }^{e} p<0.01$ represents comparison of Se deficient and Se excess groups at 8 weeks with the respective groups at 4 weeks interval.

Fig V. Effect of modulation in selenium status on the protein expression of JNK (a) and its densitometric analysis (b).

Spermatogonia: There was an increase in the number of spermatogonia staining positive for JNK in Se deficient and Se excess groups as compared to the respective Se adequate groups at four week interval. However the increase was highly pronounced in the Se deficient and excess groups at eight week interval as compared to the adequate group which rarely showed any spermatogonium staining positive for JNK.

Primary Spermatocyte: A similar trend for JNK immunostaining was observed in case of primary spermatocytes. There was an increase in the number of JNK positive cells in Se deficient and Se excess groups as compared to their respective adequate groups at both the treatment intervals.

Round Spermatid: Round spermatids also stained positive for JNK and the trend was similar to that observed in case of primary spermatocytes.

Elongated Spermatids: JNK immunostaining in elongated spermatids followed the same trend as primary spermatocyte and round spermatid at both the treatment intervals, in both Se deficient and Se excess groups. 
(A)
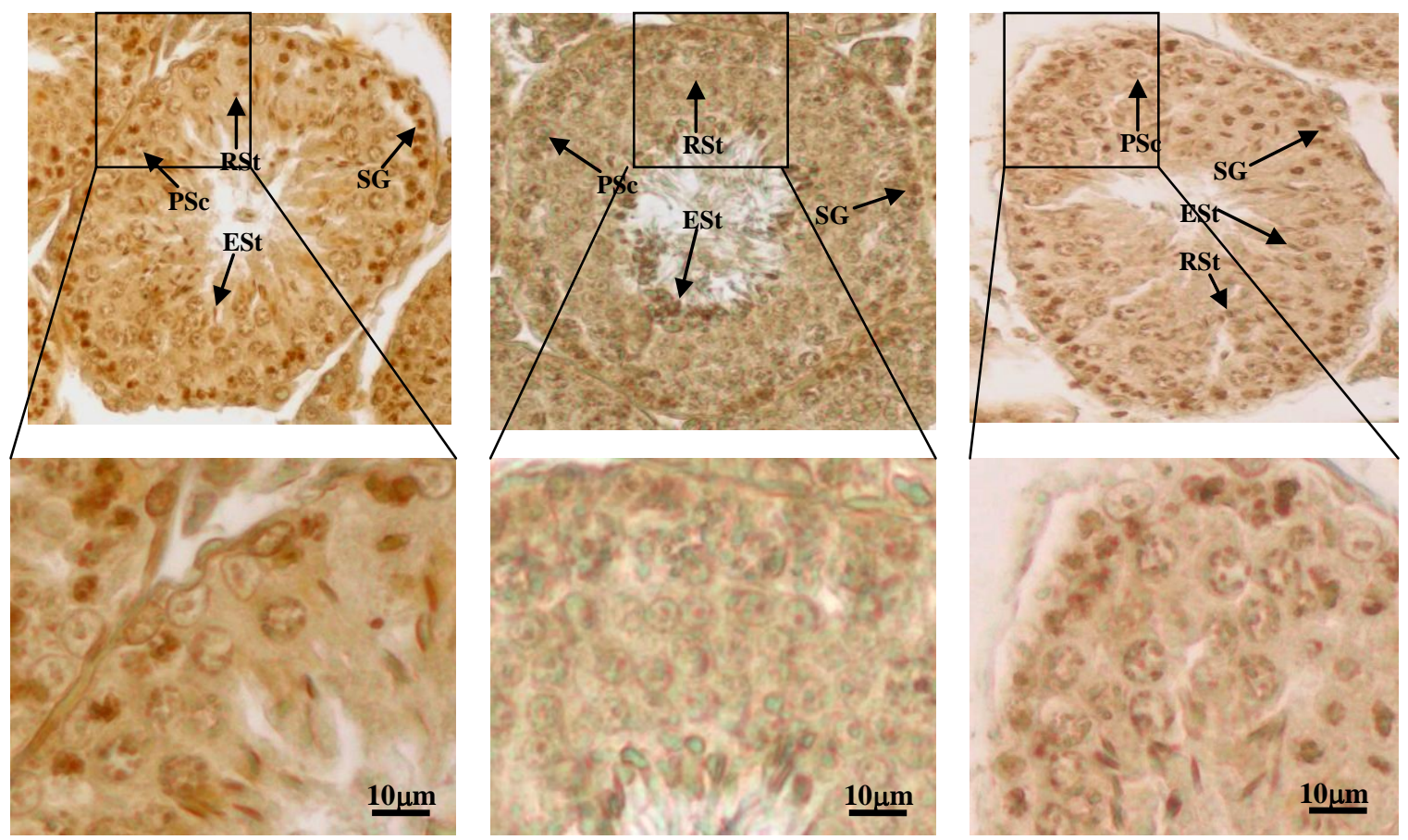

(D)

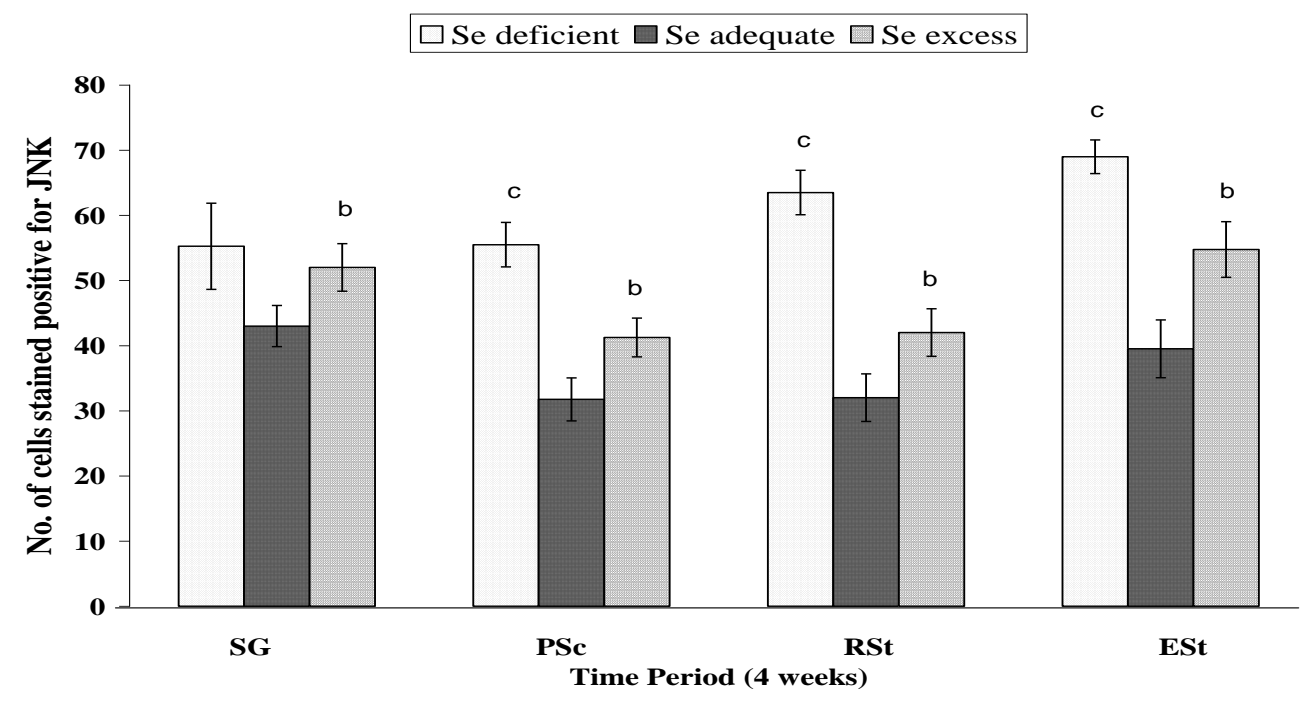

Values are Mean $\pm S D$ of 20 observations. ${ }^{b} p<0.01$ and ${ }^{c} p<0.001$ represents comparison of Se deficient and Se excess groups with respect to Se adequate group at 4 weeks.

Fig VI Photomicrograph showing effect of selenium status on JNK immunostaining in testis paraffin sections of mice fed respective diets for 4 weeks; Se Deficient (A), Se Adequate (B), Se Excess (C) and its immunokinetics (D) 
(A)

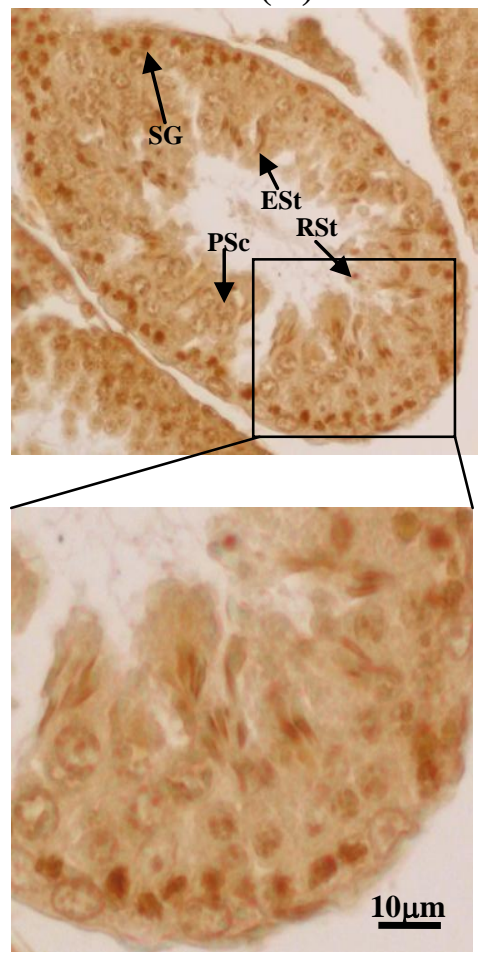

(B)

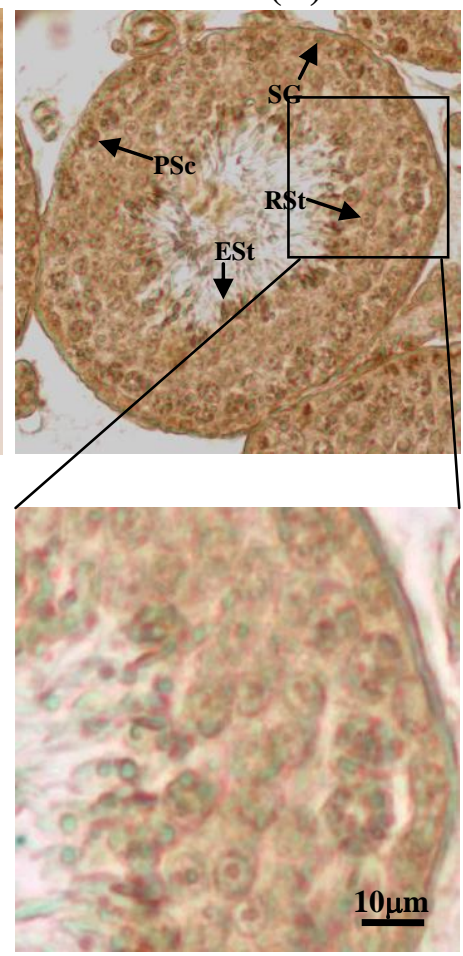

(C)

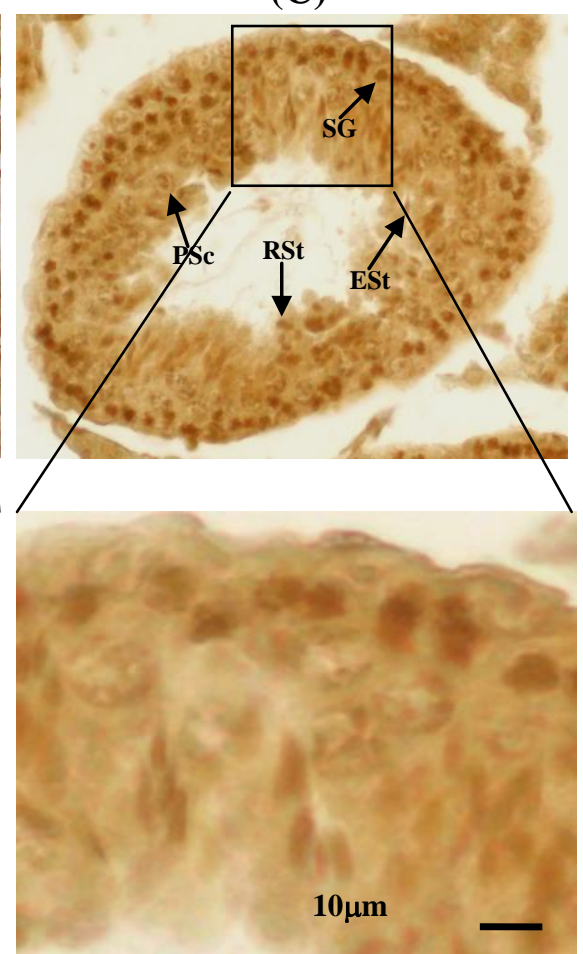

(D)

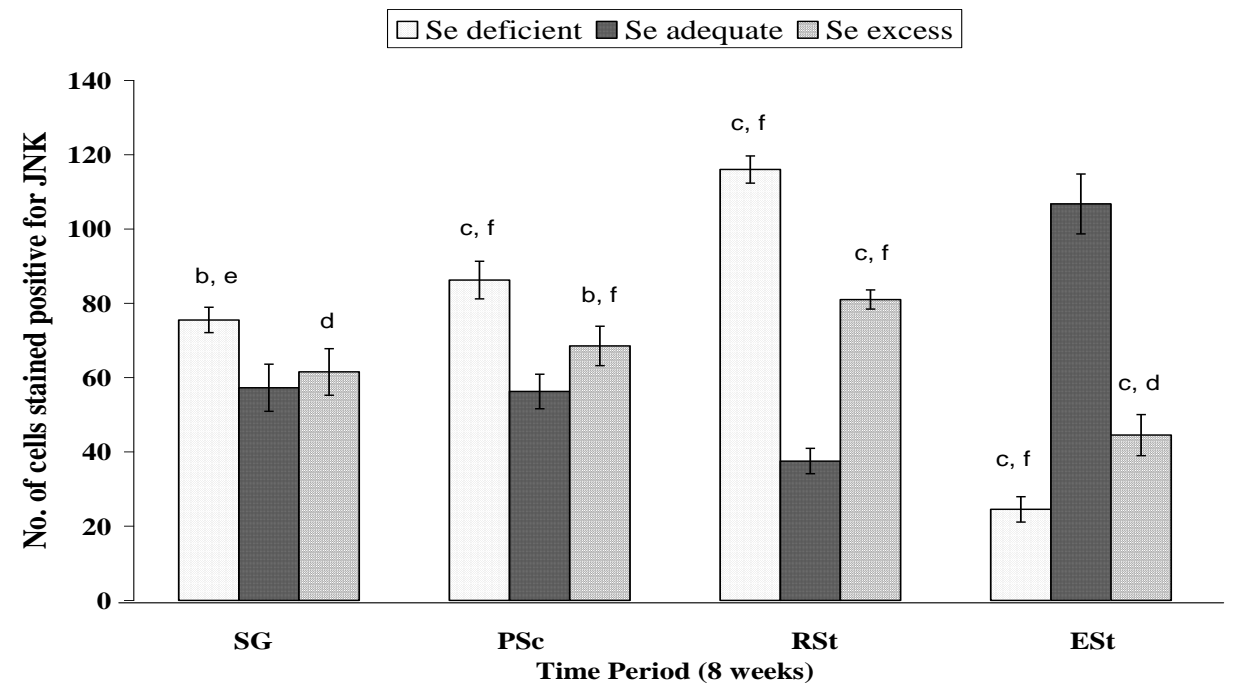

Values are Mean $\pm S D$ of 20 observations. ${ }^{b} p<0.01$ and ${ }^{c} p<0.001$ represents comparison of Se deficient and Se excess groups with respect to Se adequate groups at 4 and 8 weeks. ${ }^{d} p<0.05,{ }^{e} p<0.01$ and ${ }^{f} p<0.001$ represents comparison of Se deficient and Se excess groups at 8 weeks with the respective groups at 4 weeks interval.

Fig VII Photomicrograph showing effect of selenium status on JNK immunostaining in testis paraffin sections of mice fed respective diets for 8 weeks; Se deficient (A), Se Adequate (B),Se Excess (C) and its immunokinetics (D). 


\section{Discussion}

The present study was designed to gain insight into the molecular mechanism involved behind regulation of spermatogenesis by Se. Selenium status and GSH-Px activity was checked in testis. The reproductive potential of mice was affected at these altered selenium levels. There was a decrease in the SOD activity and reduced glutathione levels concomitant with an increase in the oxidized glutathione levels, indicative of oxidative stress. mRNA expression of GSH-Px, $\mathrm{MnSOD}$ and $\gamma \mathrm{GCS}$ was found to be altered. There was an increase in the mRNA and protein expression of JNK MAPK which was further confirmed by its immunohiostochemical localization studies.

To address the first phase of the study, the establishment of Se status in the animals under study was evaluated. A decrease in Se levels in Se deficient group as reported earlier [32] and an increase in the Se excess group at both the treatment intervals confirmed the establishment of $\mathrm{Se}$ status in the animals. These altered $\mathrm{Se}$ concentrations affect the oxidative status because of it being a known antioxidant.

Selenium exerts its physiological activity in testes through the enzyme GSH-Px, which is a major antioxidant selenoprotein [33]. A decrease in the GSH-Px activity as observed in the Sedeficient animals confirms the lowered Se levels and induction of oxidative stress in the testes [34;35]. Recently, it has been reported that Sedeficiency down regulates GSH-Px activity [36;37]. In the excess Se fed group, an increase in the GSH-Px activity was observed as compared to the Se-adequate group at both the treatment intervals. The Se excess induced toxicity can be explained on the basis of a free radical mechanism [38; 39]. Selenium at higher concentrations reacts with glutathione to form a highly reactive redox species, GSSe- (a seleopersulfide) [40; 10] which reacts with GSH to generate superoxides. GSH-Px mainly eliminates the peroxides such as fatty acid peroxides from the cell thus protecting the cells against damage caused by the free radicals and products of lipid peroxidation [41]. The reduced GSH-Px levels in the Se-deficient animals show diminished antioxidant defense mechanism and increased oxidative stress as also evidenced by the increased levels of oxidized glutathione and reduced redox ratio observed in the present study. The present study further observed reduced sperm count and percentage motility in the treated groups (Se deficient and Se excess). Several studies have been reported till date which support the above observation [35] and also address the molecular mechanism behind the changes observed. The general idea, that emerges out again points towards the specific role of GSH-Px in mediating the regulation of spermatogenesis by Se. The observation also strengthens the view that $\mathrm{Se}$ is a versatile trace element required for maintenance of male fertility [1] and any alterations in its physiologic concentrations lead to abnormal spermatogenesis [35] and hence male infertility. A decrease in the activity of antioxidant enzymes like MnSOD again shows increased accumulation of superoxide radical in animals under both treatment groups (Se deficient and $\mathrm{Se}$ excess) which further indicates the prevalent oxidative stress in the testicular environment. The activity and mRNA expression profile for MnSOD differed significantly. While, the total SOD activity decreased in both the treatment groups; the mRNA expression was found to increase. Jones et al. [42] have shown the presence of many Sp1 and $2 \kappa B$ sites in the murine SOD gene and probably these transcription factors cause its activation. Further, upregulation of MnSOD inturn would cause accumulation of $\mathrm{H}_{2} \mathrm{O}_{2}$, due to dismutation of $\mathrm{O}_{2}-$, increasing oxidative stress in the mitochondrial sheath in the sperm mid-piece and further impair motility.

The decrease in the levels of GSH in Se deficient and excess groups might be because of increased utilization of GSH in the removal of free radicals and peroxides. A concomitant increase in the level of its oxidized form; GSSG was observed. Also, the mRNA expression of the enzyme responsible for GSH synthesis; $\gamma \mathrm{GCS}$, showed a significant decrease under altered $\mathrm{Se}$ status.

Thus, confirming the existence of altered redox environment under Se stress conditions; the study was taken a step further to deal with the 
alteration in the redox sensitive transcription factor AP-1 caused by its upstream kinase JNK MAPK. Previous studies [26] from our lab report inactivation of AP-1 under Se stress conditions. To further gain insight into the molecular mechanism involved, the upstream kinase for AP1; the JNK MAPK was then studied.

The mRNA expression as well as protein expression studies revealed increased expression of JNK in the Se deficient and excess groups at both the treatment intervals. However, the increase was highly pronounced in the Se deficient group at 8 week interval. However, the phosphorylation status of JNK MAPK should be confirmed by using phosphorylated antibodies, which could not be done presently.

This increased expression of JNK in our study could be attributed to the generation of ROS which culminate in the production of oxidative stress conditions, as also confirmed by other studies where JNKs are potently activated by many kinds of stresses such as UV exposure, hyperosmosis, tumor necrosis factor- $\alpha$, interleukin-1 and heat shock [43]. The mechanism by which stress culminates in JNK activation remains largely to be determined. In this respect, Adler et al. [44] reported that UV-induced, but not heat shock- mediated JNK activation was dependent on membrane-associated components and free oxygen radicals. In addition, it has been recently suggested that ROS produced by cytokines and nitric oxide would be a second messenger to stimulate JNK, and some low molecular weight $G$ proteins (such as p21rea, Rac1 and CDC42) might be sensors in JNK activation for ROS [45]. Upregulation of MnSOD as reported in the present study leading to accumulation of $\mathrm{H}_{2} \mathrm{O}_{2}$ could also lead to phosphorylation and activation of JNK as reported by other studies [46].

Immunohistochemical localization studies also confirmed increased expression of JNK MAPK under Se stress conditions. All cells starting from spermatogonia to spermatids, showed enhanced immunostaining for JNK in all the treatment groups (Se deficient and Se excess) as compared to their respective controls which showed faint expression. Also, the number of cells positive for $\mathrm{JNK}$ immunostaining increased in all the treatment groups as compared to their controls. This, cell specific expression for JNK MAPK observed points out towards its importance as a regulator of spermatogenesis under Se stress conditions.

Previous studies [47] report enhanced expression of JNK1 during spermatogenesis in the pachytene spermatocytes, round spermatids and elongating spermatids, thereby highlighting its importance during the process.

The results obtained in this study are somewhat opposing to previous studies [26] from our lab demonstrating AP-1 inactivation under Se stress conditions. The observations also point towards inhibition of the upstream kinase for AP1 ; the JNK MAPK. Studies report that there are mutant forms of c-Jun which are deficient for DNA binding or transactivation or which were nonresponsive to JNK regulation [48]. Thus, we can conclude that, $\mathrm{Se}$ induced oxidative stress might lead to the formation of mutant form of cjun (AP-1 component), finally rendering it nonresponsive to regulation by JNK. Thus, while Se induced oxidative stress lead to upregulation of JNK, the upstream kinase for AP-1; the substrate (c-jun) was rendered nonresponsive. This, further suggests that JNK regulates spermatogenesis independent of AP-1 under Se stress conditions utilizing other substrates in the testicular milieu.

Thus, the present study demonstrates that JNK MAPK, an upstream kinase for AP-1 regulates spermatogenesis independently of AP-1 under Se stress conditions. The decrease in reproductive potential as observed in the present study in the form of decreased sperm count and motility might result from the alteration in the redox environment of the testicular compartment.

\section{Acknowledgements}

Authors acknowledge the financial support provided by Life Sciences Research Board, Defense Research and Develpoment Organization (DRDO), Govt of India, New Delhi (India).

\section{References}


1. Maiorino, M.; Flohe, L.; Roveri, A.; Steinert, P.; Wissing, J. B.; Ursini, F. Selenium and reproduction, Biofactors, 1999, 10,251-256.

2. Combs, G. F. Jr.; Gray, W. P. Chemopreventive agents: Selenium, Pharmacol Ther, 1998, 79,179-192.

3. Allan, C. B.; Lacourciere, G. M.; Stadtman, T. C. Responsiveness of selenoproteins to dietary selenium, Annu Rev Nutr, 1999,19,1-16.

4. Borchert, A.; Savaskan, N. E.; Kuhn, H. Regulation of expression of the phospholipids hydroperoxide/sperm nucleus glutathione peroxidase gene, Tissuespecific expression pattern and identification of functional cis- and transregulatory elements, J Biol Chem, 2003,278,2571-2580.

5. Maiorino, M.' Scapin, M.; Ursini, F; Biasolo, M.; Bosello, V.; Flohe, L. Distinct promoters determine alternative transcription of gpx-4 into phospholipids-hydroperoxide glutathione peroxidase variants, J Biol Chem, 2003,278,34286-34290.

6. Lei, X. G.; Evenson, J. K.; Thompson, K. M.; Sunde, R. A. Glutathione peroxidase and phospholipids hydroperoxide glutathione peroxidase are differentially regulated in rats by dietary selenium, J Nutr, 1995,125,14381446.

7. Nayernia, K.; Diaconu, M.; Aumuller, G.; Wennermuth, G.; Schwandt, I.; Kleene, K.; Kuehn, H.; Engel, W. Phospholoipd hydroperoxide glutathione peroxidase expression pattern during testicular development in mouse and evolutionary conservation in spermatozoa, Mol Reprod Dev, 2004,67,458-464.

8. Foresta, C.; Flohe, L.; Garolla, A.; Roveri, A.; Ursini, F.; Maiorino, M. Male fertility is linked to the selenoprotein phospholipid hydroperoxide glutathione peroxidase, Biol Reprod, 2002,67,967-971.

9. Sachdev, S. W.; Sunde, R. A. Selenium regulation of transcript abundance and translational efficiency of glutathione peroxidase- 1 and -4 in rat liver, Biochem $\mathrm{J}$, 2001,357, 851-858.

10. Shen, H.; Yang, C.; Ding, W.; Liu, J.; Ong, C. Superoxide radical-initiated apoptotic signaling pathway in selenite-treated HepG2 cell: Mitochondria serve as the main target, Free Radic Biol Med, 2001,30,9-21.

11. Frost, D. V.; Lish, P. M. Selenium in biology, Annu Rev Pharmacol, 1975,15,259- 284.

12. Bansal, M. P.; Mukhopadhyay, T.; Scott, J.; Cook, R. G.; Mukhopadhyay, R.; Medina, D. DNA sequencing of a mouse liver protein that binds selenium: implications for selenium's mechanism of action in cancer prevention, Carcinogenesis, 1990,11,2071-2073.

13. Handel, M. L.; Watts, C. K. W.; DeFazio, A.; Day, R. O.; Sutherland, R. L. Inhibition of AP1 binding and transcription by gold and selenium involving conserved cysteine residues in Jun and Fos, Proc Natl Acad Sci USA, 1995,92, 4497-4501.

14. Kim, I. Y.; Stadtman, T. C. Inhibition of NF$\kappa \mathrm{B}$ DNA binding and nitric oxide induction in human $\mathrm{T}$ cells and lung adenocarcinoma cells by selenite treatment, Proc Natl Acad Sci USA, 1997,94,12904-12907.

15. Seger, R.; Krebs, E. G. The MAPK signaling cascade, FASEB J, 1995,9,726-735.

16. Minden, A.; Karin, M. Regulation and function of the JNK subgroup of MAP kinases, Biochem Biophys Acta, 1997,1333,F85-F104.

17. Ip, Y. T.; Davis, R. J. Signal transduction by the c-Jun N-terminal kinase (JNK)-from inflammation to development, Curr Opin Cell Biol, 1998,10,205-219.

18. Marshall, C. J. Specificity of receptor tyrosine kinase signaling: Transient versus sustained extracellular signal-regulated kinase activation, Cell, 1995,80,179-185.

19. Han, J.; Lee, J. D.; Bibbs, L.; Ulevitch, R. J. A MAP kinase targeted by endotoxin and hyperosmolarity in mammalian cells, Science, 1994,265,808-811.

20. Chen, Y. R.; Weng, X.; Templeton, D.; Davis, R.; Tan, T. H. The role of c-Jun N-terminal kinase (JNK) in apoptosis induced by ultraviolet $\mathrm{C}$ and gamma radiation. Duration of JNK activation may determine cell death and proliferation, J Biol Chem, 1996,271,3192931936.

21. Park, J.; Kim, I.; Oh, Y. J.; Lee, K. W.; Han, P. L.; Choi, E. J. Activation of c-Jun Nterminal kinase antagonizes an anti-apoptotic 
action of Bcl-2, J Biol Chem, 1997,272,16725-16728.

22. Sluss, H. K.; Barrett, T.; Derijard, B.; Davis, R. J. Signal transduction by tumor necrosis factor mediated by JNK protein kinases, Mol Cell Biol, 1994,14,8376- 8384.

23. Ginn-Pease, M. E.; Whisler, R. L. Redox signals and NF-kappaB activation in T cells, Free Radic Biol Med, 1998, 25,346-361.

24. Rahman, I.; MacNee, W. Oxidative stress and regulation of glutathione in lung inflammation, Eur Res J, 2000,16,534-554.

25. Ranawat, P.; Bansal, M. P. Decreased glutathione levels potentiate the apoptotic efficacy of selenium: possible involvement of p38 and JNK MAPKs-in vitro studies, Mol Cell Biochem, 2008,309,21-32.

26. Shalini, S.; Bansal, M. P. Role of selenium in regulation of spermatogenesis: Involvement of activator protein 1, Biofactors, 2005,23,151162.

27. Burk, R. F. Production of selenium deficiency in rat, Method Enzymol, 1987,143,307-313.

28. Hasunuma, R.; Ogawi, T.; Kawaniska, Y. Fluorometric determination of selenium in nanogram amounts in biological materials using 2,3- diaminonaphthalene, Anal Biochem, 1982,126,242-245.

29. Paglia, D. E.; Valentine, W. N. Studies on the quantitative and qualitative characterization of erythrocyte glutathione peroxidase, J Lab Clin Med, 1967,70,158-168.

30. Hissin, P. J.; Hilf, R. A Fluorometric method for determination of oxidized and reduced glutathione in tissues, Anal Biochem, 1976,74,214-226.

31. Kono, Y. Generation of superoxide radical during autoxidation of hydroxylamine and an assay for superoxide dismutase, Arch Biochem Biophy, 1979,186,189-195.

32. Kaur, P.; Bansal, M. P. Effect of seleniuminduced oxidative stress on the cell kinetics in testis and reproductive ability of male mice, Nutrition, 2005,21,351-357.

33. Behne, D.; Weiler, H.; Kyriakopoulos, A. Effect of selenium deficiency on testicular morphology and functions in rats, Journal Reproduction and fertility, 1996,106,291-297.
34. Kaur, P.; Bansal, M. P. Effect of oxidative stress on the spermatogenic process and hsp70 expressions in mice testes, Indian Journal of Biochemistry and Biophysics, 2003,40,246251.

35. Olson, E. G.; Winfrey, V. P.; Hill, K. E.; Burk, R. F. Sequential development of flagellar defects in spermatids and epididymal spermatozoa of selenium-deficient rats, Reproduction, 2004,127,335-342.

36. Fischer, A.; Pallauf, J.; Gohil, K.; Weber, S. U.; Packer, L.; Rimbach, G. Effect of selenium and vitamin $\mathrm{E}$ deficiency on the differential gene expression in rat liver, Biochem Biophy Res Commun, 2001,285,470-475.

37. Muller, A. S.; Pallauf, J. Down regulation of GPx 1 mRNA and the loss of GPxlactivity causes cellular damage in the liver of selenium deficient rabbits, J Anim Physiol Anim Nutr, 2002,86,273-287.

38. Chaudiere, J.; Courtin, O.; Leclaire, J. Glutathione oxidase activity of selenocystamine: a mechanistic study, Arch Biochem Biophy, 1992,296,328-336.

39. Shen, H. M.; Yang, D. F.; Ong, D. N. Induction of oxidative stress and apoptosis in sodium selenite treated human hepatoma cells (HepG2), International Journal of Cancer, 1999,81,820-828.

40. Ganther, H. E. Selenotrisulfides. Formation by the reaction of thiols with selenous acid, Biochemistry, 1968,7,2898-2905.

41. Griveau, J. F.; Dumont, E.; Renard, P.; Callegari, J. P.; Le Lannou, D. Reactive oxygen species, lipid peroxidation and enzymatic defense system in human spermatozoa, J Reprod Fertil, 1995,103,17-26.

42. Jones, P. L.; Kucera, G.; Gordon, H.; Boss, J. M. Cloning and characterization of the murine manganous superoxide dismutase-encoding gene, Gene, 1995,153,155- 161.

43. Shrode, L. D.; Rubie, E. A.; Woodgett, J. R.; Grinstein, S. Cytosolic alkalinization increases stress-activated protein kinase/c-Jun NH2-terminal kinase (SAPK/JNK) activity and p38 mitogen-activated protein kinase activity by a calcium independent mechanism, J Biol Chem, 1997,272,13653-13659. 
44. Adler, V.; Schaffer, A.; Kim, J.; Dolan, L.; Ronai, Z. UV irradiation and heat shock mediate JNK activation via alternate pathways, J Biol Chem, 1995,270,26071-26077.

45. Lander, H. M.; Milbank, A. J.; Tauras, J. M.; Hajjar, D. P.; Hempstead, B. L.; Schwartz, G. D.; Kraemer, T. T.; Mirza, U. A.; Chait, B. T.; Campbell-Burk, S.; Quilliam, L. A. Redox regulation of cell signaling, Nature, 1996,381,380-381.

46. Nelson, K. K.; Subbaram, S.; Connor, K. M.; Dasgupta, J.; Ha, X. F.; Meng, T. C.; Tonks, N. K.; Melendez, J. A. Redox-dependent Matrix Metalloproteinase-1 Expression Is Regulated by JNK through Ets and AP-1 Promoter Motifs, J Biol Chem, 2006,281,14100-14110.

47. Mahecha, A. A.; Hales, B. F.; Robaire, B. Expression of Stress Response Genes in Germ Cells During Spermatogenesis, Biol Reprod, 2001,65,119-127.

48. Maclaren, A.; Clark, W.; Black, E. J. et al vJun stimulates both cdk2 kinase activity and
G1/S progression via transcriptional repression of p21 CIP1, Oncogene, 2003,22,2383-2395.

49. Yamada, K.; Takane-Gyotoku, N.; Yuan, X.; Ichikawa, F.; Inada, C.; Nonaka, K. Mouse islet cell lysis mediated by interleukin-1induced Fas, Diabetologia, 1996,39,13061312.

50. Chambers, I.; Frampton, J.; Goldfarb, P.; Affara, N.; McBain, W,; Harrison, P. R. The structure of the mouse glutathione peroxidase gene: the selenocysteine in the active site is encoded by the termination codon TGA, EMBO J, 1986,5,1221-1227.

51. Yan, N.; Meister, A. Amino acid sequence of rat kidney gamma glutamyl cysteine synthase, J Biol Chem, 1990,265,1588-1593.

52. Ho, Y. S.; Crapo, J. D. Nucleotide sequences of cDNAs coding for rat manganese superoxide dismutase, Nucleic Acid Res, 1987,15,10070. 